\title{
On the Origin and Prevention of PAIDS (Paralyzed Academic Investigator's Disease Syndrome)
}

\author{
Presidential Address Delivered before the 78th Annual Meeting \\ of the American Society for Clinical Investigation, Washington, D. C., 3 May 1986
}

\author{
Joseph L. Goldstein \\ Departments of Molecular Genetics and Internal Medicine, University of Texas Health Science Center at Dallas, Dallas, Texas 75235
}

In my Presidential address, I will depart from the traditional philosophical discourse. Instead, I will take this occasion to describe a newly recognized clinical syndrome. This devastating disease afflicts our brightest and most promising physician-scientists, crippling them just when they should be maturing into major investigators. The syndrome is called PAIDS-Paralyzed Academic Investigator's Disease Syndrome. The recognition of PAIDS, with its characteristic signs and symptoms, has come about as a result of my five years of service on the Council of this Society.

Members of the ASCI Council have two duties-one pleasant and the other not so pleasant. The pleasant duty is to attend this meeting and to hear reports of exciting research with implications far beyond the boundaries of medicine. The Council's less pleasant duty is to review each year the careers of 250 clinical investigators who have been nominated for membership. Selecting 80 members from this pool is difficult and often unsettling - for the Council as well as for the candidate. Having one's career reviewed by the ASCI Council is like having a mid-career checkup-only the sigmoidoscopy is omitted. Each candidate is examined in intimate detail. The following questions are always asked. 1) Is the science original or derivative? 2) Is the work designed to elucidate mechanisms or is it merely descriptive? 3) How independent is the investigator? 4) Is the candidate a committed scientist actively seeking new knowledge or is he or she writing papers simply to enhance an academic position?

As a member of the Council for five years, I have examined the credentials of more than 1,000 physician-scientists who have come up for their mid-career checkups. Some of the candidates are exciting investigators of the type you've heard today. They are the "shoo-ins" for the Society. But there is another type of nominee who is much more troubling and all too common. These physicians are afflicted with PAIDS. Let me present a typical case report.

Case report-J.R.

J.R. is a 41-yr-old male who received his M.D. degree in 1970 with honors from a medical school in the Southwest. He was introduced to research during the summer of his first year in medical school when he worked in an immunology laboratory. J.R. was a scholastic success. He even authored several scientific papers prior to graduation. This performance earned him a residency in medicine at a famous University hospital in the Midwest. Again, his performance was outstanding and he became a postdoctoral fellow in a liver-gastroenterology unit at a well-

Received for publication 9 May 1986.

J. Clin. Invest.

(C) The American Society for Clinical Investigation, Inc.

0021-9738/86/09/0848/07 $\$ 1.00$

Volume 78, September 1986, 848-854 known medical school on the West Coast. His fellowship included one year of clinical duties and two years of research. During his clinical year, J.R. was struck by how little was known about liver damage in patients with hepatitis and cirrhosis. He decided to spend the next two years studying liver regeneration. During the last year of his fellowship, J.R. made an exciting discovery. He found that a crude extract from newborn rat liver stimulates growth of the liver when injected into partially hepatectomized rats. This growth factor is present only in newborn liver, it is not detectable in adult rat liver.

J.R.'s assay for the liver growth factor was complicated. It required the intravenous injection of crude cell extracts into a rat that had undergone a $30 \%$ hepatectomy. Hepatic growth was measured by injecting $\left.{ }^{3} \mathbf{H}\right]$ thymidine intravenously and measuring its incorporation into liver DNA. Despite this complexity, J.R. had clear-cut findings and his work attracted considerable attention. In 1978 at age 33 he was offered assistant professorships at several university medical centers. He chose to join a famous faculty in the Northeast. As a new faculty member, J.R. was initially given a light clinical and teaching load and was able to devote $75 \%$ of his time to research. His colleagues had high expectations that his liver growth factor would turn out to be exciting.

Over the next eight years from 1978 to 1986 J.R. carefully repeated the same experiment with minor variations. He showed that the growth factor was present in livers of newborn mice, rabbits, dogs, and humans. He also showed that growth factor activity varied with a diurnal cycle. J.R. generated publishable data, he obtained an Established Investigatorship from the American Heart Association and two NIH Research Grants, and in $\mathbf{1 9 8 5}$ he was promoted to Associate Professor with tenure.

Despite these symbols of academic success, it is fair to state that our knowledge of the liver growth factor has not advanced significantly since J.R.'s original observation as a postdoctoral fellow. For the past 10 years, J.R. has caressed and massaged the problem instead of exposing it. The real challenge would be to isolate the liver growth factor and to determine its true role in physiology. This would require that J.R. reduce his complicated hepatectomy assay to an isolated cell system in which the growth factor could be measured more conveniently. With such an assay J.R. could purify the factor and learn about its structure and function. He could make antibodies. He might even clone its gene.

In 1986, studying a growth factor without purifying it is like trying to decide whether a patient has a brain tumor without employing a CAT scan, or trying to diagnose a myocardial infarction without an EKG. One is not taking advantage of the tools that have brought modern science, like modern medicine, out of the dark ages. The biologic phenomenon that J.R. has exposed is exciting. The opportunity for new knowledge is enormous and the potential for shedding light on liver disease is real. 
But J.R. cannot capitalize on his own observation. He is scientifically paralyzed.

\section{Analysis of paralysis}

Why is J.R. paralyzed? What is the origin of his PAIDS? His problem can be summarized in four words-lack of appropriate training. During J.R.'s postdoctoral fellowship in a GI-liver unit, he did not learn how to reduce a complex physiologic phenomenon to its essential elements. He did not learn how to work with isolated cells, to purify a protein, to make an antibody, or to run an SDS gel. These tools should be available to anyone who works on growth factors.

I do not mean to deprecate the importance of pure clinical research. There will always be a need for clinical scholars who make observations on patients. Such work is the beginning of all medical advance. If J.R. were attempting to do pure clinical research, his training would be appropriate. But J.R. has chosen a more fundamental route. He wants to understand a new growth factor, yet he is paralyzed.

PAIDS is a common affliction among nominees to the ASCI. No one would care about PAIDS if it affected only intellectual dullards with no scientific potential. But that is not the case. PAIDS is tragic because it afflicts our most intelligent, curious, and ambitious young physicians just when they should be blossoming into mature medical scientists.

How can we prevent PAIDS? I believe that PAIDS can be prevented by a simple prescription with two ingredients (Fig. 1). One is solid training in basic science. The other is a special quality called technical courage. Technical courage is the confidence and sense of adventure that emerges from sound basic training; it is the courage to use new techniques to answer important questions; it is the courage to avoid fossilization in what one already knows.

\section{Physician-scientists with technical courage}

The best way to illustrate technical courage is to learn from people who had it (Table I). I have selected three giants of biomedical research-Archibald E. Garrod, the father of biochemical genetics; Karl Landsteiner, the father of immuno-

Joseph L. Goldstein, M.D.

Michael S. Brown, M.D.
Table I. Virtuoso Performance in Biomedical Research: Physician-Scientists with Technical Courage

- Archibald E. Garrod - Father of Biochemical Genetics

- Karl Landsteiner - Father of Immunochemistry

- Rudolph Schoenheimer - Father of Molecular Biochemistry

chemistry; and Rudolph Schoenheimer, the father of molecular biochemistry. Like J.R., Garrod, Landsteiner, and Schoenheimer were curious physicians who were stimulated by clinical observations early in their careers. But unlike J.R., each had the basic training and the courage to explore the clinical question that he had exposed. As I discuss their careers, you will see that each of them could well have fallen into the same trap as J.R. Yet, this did not happen. Let's begin with Archibald Garrod.

ARCHIBALD E. GARROD: FATHER OF BIOCHEMICAL GENETICS. Archibald E. Garrod lived from 1857 to 1936 . He was the outstanding clinician in London at the turn of the century (Fig. 2). He eventually succeeded William Osler as Regius Professor of Medicine at Oxford. As a young physician in the 1880's and 90's, Garrod published several clinical papers, including a short book on the usefulness of the recently developed laryngoscope and a number of descriptive case reports on rheumatoid arthritis, gout, and rheumatic chorea.

In the early 1890 's, Garrod observed a patient with chorea who had reddish-brown urine. He was convinced that identifcation of the urinary pigment would provide a clue to the patient's chorea. For a clinician in the 1890's to isolate a new pigment from the urine would be as challenging as it now is for a clinician to isolate a new gene. Nevertheless, Garrod was determined to master the chemical skills necessary to isolate molecules from the urine. For this purpose, when he was 35 years of age, Garrod, the pure clinician, made a highly unorthodox move: he joined the laboratory of Frederick Gowland Hopkins, the leading biochemist in London. Hopkins is the person who discovered that chemical reactions are catalyzed by enzymes. Hopkins also proved the existence of vitamins, for which he received the Nobel Prize in 1929. Garrod acquired from Hopkins

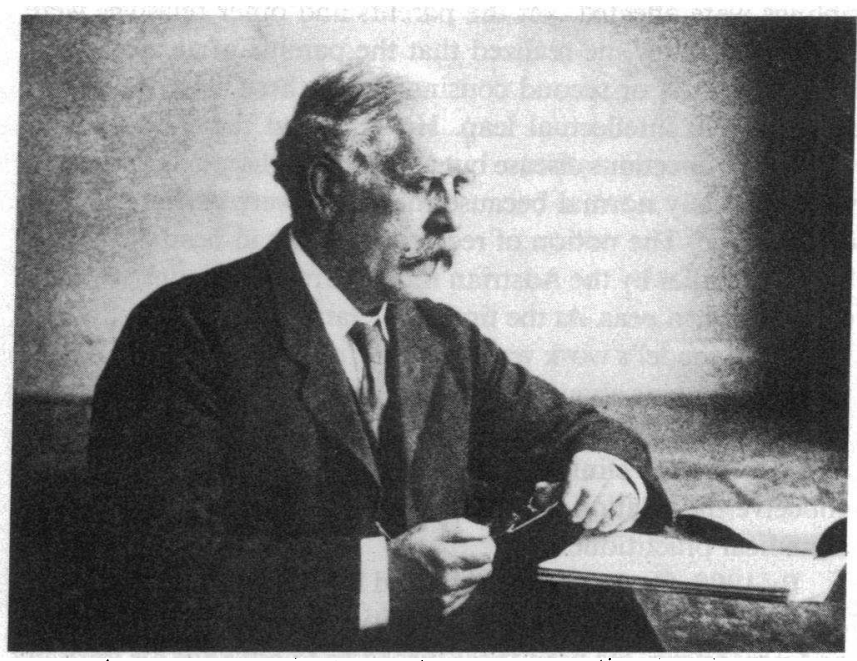

Figure 2. Archibald E. Garrod, 1857-1936. (Reproduced with permission from The Royal Society of London.)

Figure 1. Prescription for preventing PAIDS. 
an understanding of biochemistry. He learned about the emerging field of enzymology, and he learned how to use a spectroscope to analyze chemicals in the urine. With his new skills Garrod examined hundreds of specimens of urine in an attempt to isolate molecules in pure form. He discovered that porphyrins were found in the urine of healthy individuals and were elevated nonspecifically in the urine of patients with a variety of diseases, including the original patient with chorea. So the study of pigments did not teach Garrod the secret of chorea. Although his hypothesis proved false, Garrod's training was not wasted: it allowed him to go far beyond his original goal.

In 1897, Garrod's fascination with urinary pigments brought him in touch with a patient with alcaptonuria, also known as "black urine disease." These rare patients excrete large amounts of the chemical, homogentisic acid. In the presence of air, homogentisic acid is oxidized spontaneously to a brownish black polymer, which causes the urine to turn black. The pigment also accumulates slowly in cartilage and other connective tissues, causing bluish discoloration of the sclerae and osteoarthritis.

At the time that Garrod began his studies, the prevailing view was that alcaptonuria was caused by some peculiar infectious organism that invaded the intestine and formed a black pigment that was absorbed into the blood. This was, after all, the golden age of bacteriology. Garrod doubted this theory because affected patients had black diapers immediately after birth. Garrod therefore carried out a series of balance experiments in which he measured urinary homogentisic acid in normal and affected individuals after the ingestion of a protein meal rich in phenylalanine and tyrosine. His findings were clear-cut. Homogentisic acid rose to high levels in the urine of alcaptonurics four hours after a meal, but no such rise occurred in normals. Garrod made two conclusions: first, that homogentisic acid was a normal intermediate in the catabolism of phenylalanine and tyrosine; and second, that alcaptonuria is caused by the lack of an enzyme that normally degrades homogentisic acid to a colorless product. Garrod's hypothesis was formally proved correct 55 years later in 1958 when two members of our Society-Burt LaDu and Jay Seegmiller-demonstrated directly the absence of homogentisic acid oxidase in the liver of alcaptonuric patients.

Not satisfied with a simple clinical description, Garrod went on to make observations about the familial clustering of alcaptonuria. From his analysis of 31 cases, he concluded that multiple siblings were affected, yet the parents and other relatives were normal. Astutely, he realized that the parents of alcaptonurics were often first or second cousins. From these observations he made a bold intellectual leap. He suggested that alcaptonuria was not an infectious disease but an inherited disease. The parents were clinically normal because they both were carriers of a recessive gene. The notion of recessive genes had been developed 30 years earlier by the Austrian monk, Gregor Mendel, who had studied garden peas. At the time that Garrod made his deduction in 1902, Mendel's work was just being rediscovered. The notion that observations about garden peas could be applied to animals, much less humans, was outrageously bold. By applying his basic training and his clinical insight, Garrod was the first person to conceive the relation between genes and enzymes. Not bad for a medical practitioner!

By 1908, Garrod had generalized his findings in alcaptonuria to three other rare metabolic conditions-albinism, cystinuria, and pentosuria. He used these disorders to advance his unifying theory of the inborn error of metabolism, which he first presented in his Croonian Lectures of 1908 to the Royal College of Phy- sicians of London (Fig. 3). According to Garrod's theory, alcaptonuria, albinism, cystinuria, and pentosuria were each due to a block in the normal pattern of metabolism, and each block was due to an inherited deficiency of an enzyme.

Garrod did not limit his thinking to rare inborn errors of metabolism. He was also interested in the genetic and biochemical basis of common diseases. He predicted that each human being can be distinguished from all others by possession of a unique set of enzymes encoded in his or her genes. He went on to state that common diseases are caused by the interaction of environmental factors with each individual's unique genetic makeup.

All of Garrod's ideas were way ahead of their time. Physicians did not grasp the importance of genetics, and basic scientists paid little attention to the hypotheses of a physician. The broad significance of Garrod's work was not fully appreciated until 40 years later when two basic scientists, Beadle and Tatum, rediscovered the one-gene/one-enzyme concept in their classic studies of Neurospora.

Like his ideas, Garrod's style of doing science was also far in advance of contemporary practice. Stimulated by a clinical phenomenon, he studied it with the most advanced techniques of chemical science available to him. His mastery of science gave him the courage to think about his data in an unfettered way. The combination of clinical insight and technical courage allowed him to advance novel concepts whose implications for biology extended far beyond his empirical observations. Over the $\mathbf{8 0}$ years following Garrod's work, many of the triumphs and virtuoso performances in the biomedical sciences have been made by physicians who followed Garrod's style of bringing hard science to bear on a clinical problem.

From Garrod's career, we can devise a simple formula that can be stated as follows:

clinical stimulus $\times$ basic scientific training

$$
=\text { fundamental discovery. }
$$

The enormous power of the Garrodian formula (Table II) is evident in the careers of two other scientists whom I will now briefly discuss-one well known and the other not so well known. The first is Karl Landsteiner and the second is Rudolph Schoenheimer.

KARL LANDSTEINER: FATHER OF IMMUNOCHEMISTRY. Karl Landsteiner lived from 1868 to 1943 (Fig. 4). His medical training was in pathology, and he personally performed 3,639 autopsies during the first 10 years of his career-one autopsy per day, seven days per week for 10 years. What's amazing to believe is that his major scientific discovery came in the midst of this enormous clinical load. Landsteiner's curiosity was aroused by the clinical problem of massive hemolysis and generalized tissue destruction that occurred in patients who died after blood transfusions or injections of foreign protein. He wondered whether the serum of sick patients might act on the cells of healthy individuals. This stimulated him to investigate whether red cell agglutination and hemolysis could be detected in a test tube. Fortunately, Landsteiner had a strong background in organic chemistry. He applied his chemical knowledge to the clinical problem of transfusion reactions and the result was the discovery of A, B, and $\mathrm{O}$ blood groups and the theory of chemical immunity.

One other point about Landsteiner is particularly relevant to us today. Landsteiner began his career in the late 1890's. This 


\section{THE LANCET, JuLy 4, 1908.}

\section{Che $\mathfrak{C}$ romian Pertutes}

DI

INBORN ERRORS OF METABOLISM.

Delicered before the Royal College of Physioians of London on June 1Sth, 2sidd; 25th, and Soth, 1908,

BY ARCHIBALD E. GARROD, M.A., M.D. OxON., F.R.C.P. LoND.,

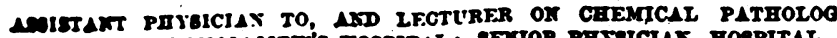

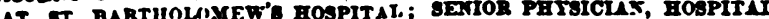

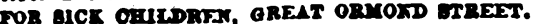

\section{LECTURE I.}

Delivered on Jwe 18th, 1900.

GENERAL $\triangle$ ND ITTRODUCTORY.

JIR. PrFisinf:xt AND FkLLOWS, - It is my first agreeable dufy to offer my sincere thanks for the honour conferred upun me in the invitation to deliver the Croonian lectures of the current year before this College. I trust that the subject which I have selected will be found to conform closely to the instructions to the lecturer, for it is one which lies upon the rery border-line of phssiology and pathology and pertains to buth sciences alike; nor is it without bearing npon the control and cure of discase, in 80 far as no study which helps to throw light upon the complex chemical processes which are carried out in the human organism can fail in the long run to strengthe'n our hands in the combat with the pathogenic iufluences which make for its destruction.

The differences of structure and form which serve to distinguish tbc various genera and species of animals and plants are among the most obvious facts of nature. For their detection no scientific training is needed, seeing that they crnnot escape the notice of eren the least cultirated intelligence. Yet with the growth of lnowledge we have leamed to reognise the uniformity which nnderlies this 80 apparent and that within that boundary, which has no real finality, rigid uniformity reigns. Buch a conception is at variance with any evolutionary conception of the nature and origin of species. The existence of chemical individuality follows of necessity from that of chemical specificity, but we should expect the differences between individuals to be still more subtle and difficult of detection. Indications of their existence arc seen, even in man, in the various tints of skin, hair, and eyes, and in the quantitatire differences in those portions of the end-products of metabolism which are endogenous and are not affected by diet, such as recent researches have revealed in increasing numbers. Even those idiosyncrasies with regard to drugs and articles of food which are eummed up in the proverbial saying that what is one man's meat is another man's poison presumably hare a chemical basis.

Uipon chemical as upon structural variations the factors which make for exolution have worked and are working. Eridences of this are to be detected in many directions, as, for example, in the delicate selective power of the kidneys, in xirtue of which they are enabled to bold back in the circulation the essential proteins of the blood but at the same time allow free passage to other proteins which are foreign to the plasma, such as hrpoglobin, egg albumin, and the Bence-Jones protein, when these are present in any but quite small amounts. The working of these factors is also seen in the rarious protective mechanisms against chemical poisons, such as that which arerts the depletion of the fixed alkalies of the organism by the neutralisation of abnormal supplies of acids by ammonia. This mechanism is well developed in the carnivora and in man, but in regetivonous animals which from the nature of thair diet are little exposed to acidosis it appears to be wanting.

Eren in the normal metabolic processes the working of ench influences may be traced, as in the power which the organism poesesses of destroying the benzene ring of those aromatic anino-acids which enter into the composition of proteins and cannot therefore be regarded as apbstances foreign to the body; whereas the benzene ring of foreigr

Figure 3. Title page from Garrod's classic publication in which he advanced the concept of the inborn error of metabolism.

was the heyday of bacteriology. The brilliant work of Pasteur and Koch had opened the door to the understanding of bacterial infection, and glory was available to any young scientist who chose bacteriology as a career. He had only to find an unexplored disease and isolate the causative bacterium. Early in his career in 1908, Landsteiner succumbed to this attraction, and he isolated a new causative organism-only it wasn't a bacterium. It was a virus-the polio virus to be precise. This breakthrough caused an immediate flurry of activity in research laboratories in the United States as well as in Europe. Landsteiner had to choose between continuing to work in the popular field of infectious disease or to pioneer a new field of immunology. He chose the more risky, but novel route. This choice was based on his early scientific training, which was not in bacteriology but in chemistry. As a student Landsteiner had studied with a great chemist, Emil Fischer. This training gave him the technical courage to try something new, and the result was a new field of science-immunochemistry (Table II).

RUDOLPH SCHOENHEIMER: FATHER OF MOLECULAR BIOCHEMISTRY. Our next pioneer, Rudolph Schoenhei-

Table II. The Garrodian Formula for Scientific Success

\begin{tabular}{|c|c|c|c|c|c|}
\hline Physician-scientist & Clinical stimulus & $\times$ & Scientific training & $=$ & Fundamental discovery \\
\hline Archibald Garrod (1857-1936) & Black urine & $x$ & Chemistry & $=$ & One gene encodes one enzyme \\
\hline Karl Landsteiner (1868-1943) & Transfusion reactions & $x$ & Chemistry & $=$ & $\begin{array}{l}\text { ABO blood groups; Principles of } \\
\text { immunochemistry }\end{array}$ \\
\hline Rudolf Schoenheimer (1898-1941) & Hypercholesterolemia and atherosclerosis & $x$ & Chemistry & $=$ & $\begin{array}{l}\text { Isotopes as tools for biological } \\
\text { research; Theory of dynamic } \\
\text { steady state }\end{array}$ \\
\hline J.R. (1945-） & Liver regeneration & $x$ & None & $=$ & None \\
\hline
\end{tabular}




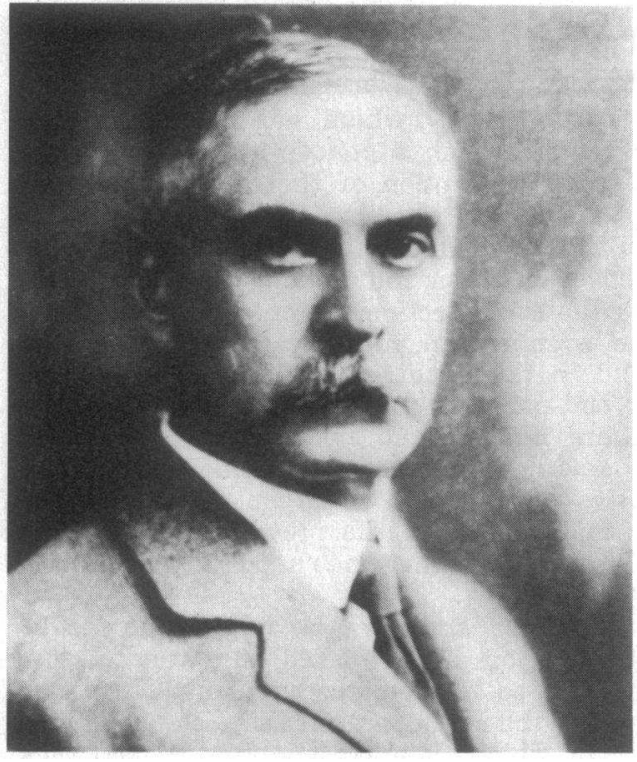

Figure 4. Karl Landsteiner, 1868-1943. (Reproduced with permission from the U. S. National Academy of Sciences.)

mer, lived only 43 years-from 1898 to 1941 (Fig. 5). He is considered by many historians to be the single individual most responsible for ushering in the modern era of molecular biochemistry. Schoenheimer was a physician who began his career in the mid 1920's as a pathologist, studying atherosclerosis in the cholesterol-fed rabbit. He worked with a great mentor, Ludwig Aschoff, who was the world's expert on the pathology of atherosclerosis. Schoenheimer became fascinated with the fourring structure of cholesterol. He wondered how such a complex

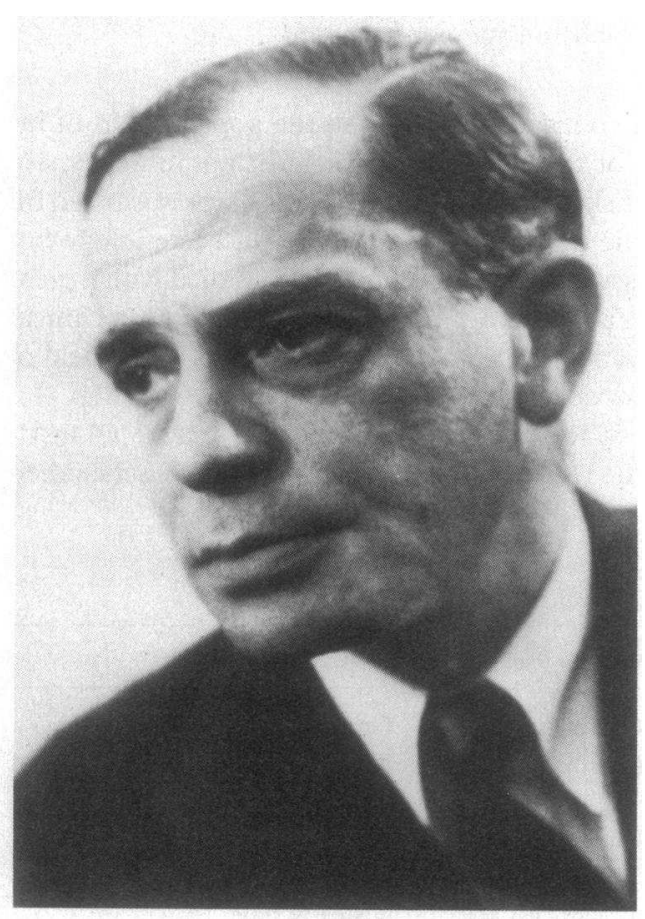

Figure 5. Rudolph Schoenheimer, 1898-1941. (Reproduced with permission from Springer-Verlag New York Inc.) molecule could be synthesized. Realizing that his clinical background did not equip him with the technical tools necessary to approach this problem, he obtained postgraduate training in two of the leading organic chemistry laboratories in Germany.

In the early 1930's, Schoenheimer attempted to figure out the cause of the high blood cholesterol level in a patient with severe hypercholesterolemia. His first approach was to use the classic chemical balance method of the type that Garrod had used 30 years earlier. Schoenheimer measured the sterol output in the stool after the patient consumed varying amounts of cholesterol in the diet. Unlike Garrod's findings with alcaptonuria, Schoenheimer's findings with hypercholesterolemia were anything but clear-cut. He was totally unable to deduce the mechanism for the accumulation of cholesterol in the blood. This frustration made Schoenheimer acutely aware of the weakness of balance studies. In a famous metaphor, he compared the clinical balance study to the working of a chewing gum machine. He wrote: "A penny brings forth one package of chewing gum; two pennies bring forth two. Interpreted according to the reasoning of balance physiology, the first observation is an indication of the conversion of copper to gum; the second [observation] constitutes proof."

Soon after publishing his clinical study on hypercholesterolemia, Schoenheimer was forced to leave Nazi Germany, and in 1933 at age 34 he emigrated to New York City, where he was offered a job in the Biochemistry Department at Columbia University College of Physicians and Surgeons. Shortly after arriving at Columbia, Schoenheimer hit upon a completely new way to decipher the complexities of cholesterol metabolism in the whole body. He conceived the novel idea of using isotopes as molecular tracers for biochemical events. Isotopes had only recently been isolated by nuclear physicists. They had never before been used as biological tracers for probing physiological events. Using heavy isotopes of hydrogen and nitrogen, Schoenheimer became the first to glimpse body chemistry in action. Between 1934 and 1941 he synthesized numerous isotopically labeled compounds that allowed him to trace the fate of cholesterol, fatty acids, and amino acids throughout the body of animals and humans. He made the surprising finding that complex molecules, such as cholesterol, triglycerides, and proteins, were constantly turning over as a result of continual synthesis and degradation. This finding went against existing dogma, which stated that such molecules were stable and unchanging constituents of cells and organs. These exciting data formed the basis of Schoenheimer's theory of the dynamic steady state, which was presented in 1941 in the Durnham Lectures at Harvard Medical School and published in a famous monograph called The Dynamic State of Body Constituents (Fig. 6). Shortly after he completed this monograph, Schoenheimer's brilliant career ended tragically with his death at age 43 .

By the time of his death, Schoenheimer had surrounded himself at Columbia with a large group of brilliant students and postdoctoral fellows who then went on to extend his pioneering ideas in dazzling fashion. Five of Schoenheimer's students were subsequently elected to the National Academy of Sciences, and one of them, Konrad Bloch, was awarded the Nobel Prize in Medicine for work that was begun with his mentor. Within several years after his death, Schoenheimer's students carried out a series of classic experiments whose results are still taught to our medical students. For example, they elucidated the biosynthetic pathways for cholesterol, creatine, uric acid, and porphyrins; they showed, in clinical studies of a pregnant woman, that 


\section{THE DYNAMIC STATE OF BODY CONSTITUENTS}

BY

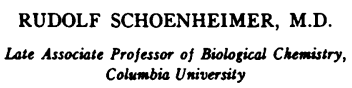

RUDOLF SCHOENHEIMER, M.D Late Associate Professor of Biological Chemistry,
Columbia University

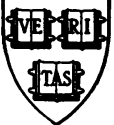

CAMBRIDGE, MASSACHUSETT HARVARD UNIVERSITY PRESS

I942

Figure 6. Title page from Schoenheimer's classic monograph in which he advanced the concept of the dynamic steady state for body constituents.

steroid hormones were formed from cholesterol; they measured the synthesis and turnover of antibodies; and they determined that the life-span of a red blood cell in humans was 120 days.

Schoenheimer was clearly a towering figure whose work profoundly influenced virtually all areas of biomedical research. It is impossible to capture here the excitement of the transformation in scientific thought that resulted from Schoenheimer's isotopic experiments and his theory of the dynamic steady state. As clinical investigators, we can take pride in the fact that the key to Schoenheimer's success was his medical background, which gave him the original stimulus, the breadth, and the flexibility that allowed him to unify a broad range of empirical observations into powerful biomedical theories (Table II).

Although Schoenheimer was never a member of the ASCI, his style of research spread like wildfire through our Society thanks to DeWitt Stetten, who was one of his original students. Stetten became the head of an exciting laboratory at the NIH and launched the careers of many of our Society's most distinguished physician-scientists. Jim Wyngaarden, Jay Seegmiller, Holly Smith, Leonard Laster, Kurt Isselbacher, Paul Marks, Howard Hiatt, Daniel Foster, and the late Gordon Tomkins are just a few of the many members of our Society who trained in Stetten's laboratory.

The comparison between Schoenheimer and Garrod illustrates an additional point about clinical research. Garrod made his entire career on balance studies-Schoenheimer found them inadequate. The difference between the two men was time-30 years. Garrod advanced our understanding of biochemical genetics by applying a new technique-that is, chemical balance. By Schoenheimer's time the questions had become more sophisticated and fundamental. They could no longer be answered by simple input-output analysis. Schoenheimer's questions could only be answered by tracing the fate of specific molecules in and out of cells and tissues. So Schoenheimer had to invent a new method. This is the way of all scientific progress.

\section{Back to J.R. and PAIDS}

Let us now return to J.R. Where does he fit in this scheme? J.R. has the clinical stimulus. He has the intelligence, the curiosity, and the drive. But he does not have the technical skill or conceptual insight to reduce a complex clinical phenomenon to a manageable biochemical problem. In a real sense he is paralyzed (Table II).

How can we help J.R. and the many other clinical investigators who are afflicted with PAIDS? If there is one lesson to be learned from the careers of Garrod, Landsteiner, and Schoenheimer, it is that PAIDS can be prevented by a combination of basic science training and technical courage.

\section{Prevention of PAIDS by basic science training and technical courage}

In order to apply the tools of basic science, physicians must learn to think like basic scientists. They must acquire technical ability, taste in evaluating experiments, and a sense of creative adventure. This combination can only come from intensive training in strong departments of basic science. I do not subscribe to the currently popular notion of a research fellowship that is intermingled with clinical training. Medical scientists must concentrate intensively on science in an uninterrupted fashion during their formative scientific years, and they must be equally intense about medicine during their clinical years. Only then will the two parts of Garrod's formula be strong enough to create a powerful mixture. If such dual training is to be possible, medical schools must have forward-looking clinical departments that encourage physicians to delve deeply into basic science. They also must have first-rate departments of basic science that are enthusiastic about training M.D.'s in the highest scientific art. Such enthusiasm can only come when the basic scientists realize that the young clinical trainees are not entering their laboratories for some superficial coaching on a particular technique-which is too often the case today. The partnership between basic and clinical scientists will flourish only when the basic scientists are convinced that the clinical scholars are committed to a scientific course that is as intense as that of the typical Ph.D. postdoctoral fellow.

As clinicians, we can take one more action to foster this partnership. We can provide financial support. Most funds from private donors are given to clinicians because the donors wish to cure a dreaded disease such as cancer, heart disease, or Alzheimer's disease. As forward-looking clinical investigators, we must actively divert a generous portion of these funds to basic science departments. These additional funds should allow the basic science departments to recruit and support strong scientists who will serve as tutors to the clinical scholars. If physicianscientists are to become creators and innovators in medical research à la Garrod, Landsteiner, and Schoenheimer, it is absolutely essential that clinical departments assume a leadership role in assuring the financial support of strong departments of basic science.

Finally, it will be necessary for clinical departments to welcome back their scientifically trained colleagues at the end of their 3- or 4-year sojourn in a basic science laboratory. We must reexcite them about the joys of clinical medicine and encourage them to participate fully in the department's activities. Physician-scientists must be spared the "fee-for-service" obligation that is driving many of our clinical departments. They should be allowed to approach patients from a scholarly, aca- 
demic viewpoint. The full-time clinicians should see themselves as teachers of the physician-scientists, not as rivals.

In this Utopia of academic enterprise, new discoveries will flow, and the entire faculty will glow with pride in the combination of clinical and scientific talent that has been assembled. And last but not least, the Council of the ASCI will finally be able to relax at their meetings without the dreadful fear of electing someone into our Society who has a contagious case of PAIDS.

\section{Acknowledgment}

Writing speeches of this type is generally not the most enjoyable or intellectually stimulating way to spend one's time. However, preparing this speech-from the initial ideas to the final written word-turned out to be fun and exciting thanks to the creative input of Michael S. Brown, my long-term scientific collaborator.

\section{Selected References}

\section{Archibald E. Garrod}

Beadle, G. W. 1959. Genes and chemical reactions in neurospora. Science (Wash. DC). 129:1715-1719.

Bearn, A. G., and E. D. Miller. 1979. Archibald Garrod and the development of the concept of inborn errors of metabolism. Bull. Hist. Med. 53:315-328.

Childs, B. 1970. Sir Archibald Garrod's conception of chemical individuality: a modern appreciation. N. Engl. J. Med. 282:71-77.

Garrod, A. E. 1908. The Croonian lectures on inborn errors of metabolism. Lancet. ii:1-7, 73-79, 142-148, and 214-220.

Garrod, A. E. 1931. The Inborn Factors in Disease. Oxford University Press, London. 1-160.

Harris, H. 1963. Garrod's Inborn Errors of Metabolism. Oxford University Press, London. 1-207.

Hopkins, F. G. 1938. Archibald Edward Garrod, 1857-1936. Obituary Notices of Fellows of the Royal Society. 2:225-228.

Horowitz, N. H. 1985. The origins of molecular genetics: one gene, one enzyme. Bioessays. 3:37-39.

La Du, B. N., V. G. Zannoni, L. Laster, and J. E. Seegmiller. 1958. The nature of the defect in tryrosine metabolism in alcaptonuria. J. Biol. Chem. 233:251-260.

\section{Karl Landsteiner}

Goebel, W. F. 1975. The golden era of immunology at the Rockefeller Institute. Perspect. Biol. Med. 18:419-426.

Heidelberger, M. 1969. Karl Landsteiner June 14, 1868-June 26, 1943. Biogr. Mem. Nat. Acad. Sci. 40:176-210.

Levine, P. 1961. A review of Landsteiner's contributions to human blood groups. Transfusion. 1:45-52.

Peyton, R. 1947. Karl Landsteiner, 1868-1943. Obituary Notices of Fellows of the Royal Society. 5:295-324.

Speiser, P. 1973. Karl Landsteiner. In Dictionary of Scientific Biography, Vol. VII. C. C. Gillipsie, editor. Charles Scribner's Sons, New York. 622-625.

\section{Rudolph Schoenheimer}

Clarke, H. T. 1941. Rudolf Schoenheimer, 1898-1941. Science (Wash. DC). 94:553-554.

Kohler, R. E., Jr. 1977. Rudolf Schoenheimer, isotopic tracers, and biochemistry in the 1930's. Historical Studies in the Physical Sciences. 8:257-298.

Ratner, S. 1979. The dynamic state of body proteins. Ann. N.Y. Acad. Sci. 325:189-209.

Nachmansohn, D. 1979. German-Jewish Pioneers in Science, 1900-1933. Springer-Verlag New York Inc. 357-360 (and xvii).

Schoenheimer, R. 1931. New contributions in sterol metabolism. Science (Wash. DC). 74:579-584.

Schoenheimer, R. 1933. Uber eine Störung der Cholesterin-Ausscheidung: Ein Beitrag zur Kenntnis der Hypercholesterinämien. (About a disturbance in cholesterol excretion: a contribution to our knowledge of hypercholesterolemia.) Z. Klin. Med. 123:749-763.

Schoenheimer, R. 1937. The investigation of intermediary metabolism with the aid of heavy hydrogen. Harvey Lect. 32:122-144.

Schoenheimer, R. 1942. The Dynamic State of Body Constituents. Harvard University Press, Cambridge, MA. 78 pp.

Schoenheimer, R., and D. Rittenberg. 1938. The application of isotopes to the study of intermediary metabolism. Science (Wash. DC). 87: 221-226.

Stetten, D., Jr. 1982. Rudi. Perspect. Biol. Med. 25:354-368. 